\title{
Can climate warming induce glacier advance in Taylor Valley, Antarctica?
}

\author{
Andrew G. FOUNTAIN, ${ }^{1}$ Thomas A. NEUMANN, ${ }^{2}$ Paul L. GLENN, ${ }^{1 *}$ Trevor CHINN ${ }^{3}$ \\ ${ }^{1}$ Departments of Geology and Geography, Portland State University, PO Box 751, Portland, Oregon 97207, USA \\ E-mail: andrew@pdx.edu \\ ${ }^{2}$ Department of Earth and Space Sciences, Box 351310, University of Washington, Seattle, Washington 98195-1310, USA \\ ${ }^{3}$ R/20 Muir RD. Lake Hawea RD 2, Wanaka, New Zealand
}

\begin{abstract}
Changes in the extent of the polar alpine glaciers within Taylor Valley, Antarctica, are important for understanding past climates and past changes in ice-dammed lakes. Comparison of ground-based photographs, taken over a 20 year period, shows glacier advances of 2-100 m. Over the past $\sim \mathbf{1 0}^{3}$ years the climate has warmed. We hypothesize that an increase in average air temperature alone can explain the observed glacier advance through ice softening. We test this hypothesis by using a flowband model that includes a temperature-dependent softness term. Results show that, for a $2^{\circ} \mathrm{C}$ warming, a small glacier $\left(50 \mathrm{~km}^{2}\right)$ advances $\sim 25 \mathrm{~m}$ and the ablation zone thins, consistent with observations. A doubling of snow accumulation would also explain the glacial advance, but predicts ablation-zone thickening, rather than thinning as observed. Problems encountered in modeling glacier flow lead to two intriguing but unresolved issues. First, the current form of the shape factor, which distributes the stress in simple flow models, may need to be revised for polar glaciers. Second, the measured mass-balance gradient in Taylor Valley may be anomalously low, compared to past times, and a larger gradient is required to develop the glacier profiles observed today.
\end{abstract}

\section{INTRODUCTION}

The McMurdo Dry Valleys is one of the few ice-free regions in Antarctica. Consequently, it is one of the few places the glacially modified landscape can be used to infer past changes of the Antarctic ice sheet (Denton and Hall, 2000). Large changes in ice-sheet extent, relative to the scale of the dry valleys, have been documented (Hall and others, 2000; Higgins and others, 2000). In contrast, the extent of the local alpine glaciers has changed little since the Pliocene (Hall and others, 1993; Wilch and others, 1993). Yet the small changes in the alpine glaciers are important to the maintenance of the enclosed ice-covered lakes in the dry valleys and, in turn, to the ecosystems that inhabit the valleys (Fountain and others, 1999). We use repeat photography to quantify the change in extent of several glaciers over the past 20 years. To interpret these changes, we developed a numerical model to examine possible processes controlling the observed changes. Results from this study are important to several glaciological issues. First, the results bear on the possibility of using glacially modified terrain around these glaciers for paleoclimatic reconstruction. This is particularly apt in view of the climatic results obtained from the Taylor Dome ice core located about $100 \mathrm{~km}$ away (Steig and others, 2000). Second, a history of glacier advance and retreat will help define the history of icedammed lake formation and drainage, a subject important to ecological evolution within the valleys (Fountain and others, 1999). Third, we use our model to explore the response of polar alpine glaciers to climatic variations, a subject that has not been as thoroughly explored as for their temperate counterparts.

*Present address: Landau Associates, Inc., 130 Second Avenue South, Edmonds, Washington 98020, USA.

\section{SITE DESCRIPTION}

The McMurdo Dry Valleys are located in southern Victoria Land on the edge of the Antarctic continent (Fig. 1). They are named the 'dry valleys' (Scott, 1905) because the Transantarctic mountain range blocks the seaward expansion of the East Antarctic ice sheet (EAIS) and the valleys are largely empty of ice. A few outlet glaciers from the ice sheet terminate in the western ends of the valleys. Alpine glaciers populate the mountains, the largest of which reach the valley floor. Average annual air temperatures in the valleys vary between -30 and $-17^{\circ} \mathrm{C}$, and summer air temperatures typically reach only a few degrees above freezing (Doran and others, 2002b). Consequently, the glaciers in the valleys are polar and are frozen to the substrate (Cuffey and others, 2000). Melting is restricted to the glacier surface and to the $20 \mathrm{~m}$ high vertical cliffs which define the glacier margin in the ablation zone (Chinn, 1985; Fountain and others, 1998). Streams originate at the glacier termini and flow for perhaps 10 weeks during the austral summer (McKnight and others, 1999). Some of the streams discharge into perennially icecovered lakes, which are present in every valley.

The annual mass exchange of these polar glaciers is relatively small compared to temperate glaciers. About $0.1 \mathrm{~m}$ of snow accumulates in the upper zones and about $0.1-0.2 \mathrm{~m}$ of ice is lost from the ablation zone (Bull and Carnein, 1970; Chinn, 1980; Fountain, unpublished data). Ablation in the accumulation zones is limited to sublimation and wind erosion. In the ablation zone, about $40-80 \%$ of the mass loss occurs through sublimation and the remainder is lost by melting (Lewis and others, 1998).

The glacial history of the valleys is dominated by the activity of the EAIS. Taylor Glacier advanced almost to the eastern end of Taylor Valley about 70-100 kyr BP (Hendy and others, 1979; Higgins and others, 2000). During the Last Glacial Maximum, lowered sea levels caused the Ross Ice 
Shelf to advance. A lobe of the Ross Ice Shelf entered Taylor Valley about $23.8 \mathrm{kyr}$ BP (Hall and others, 2000) and blocked the seaward opening of Taylor Valley. A large ice-dammed lake formed, Lake Washburn, which persisted until about 6 kyr BP (Hall and Denton, 1995). In contrast to these dramatic changes, geologic evidence indicates that the alpine glaciers of the valley have not significantly advanced from their present position since the Pliocene (Hall and others, 1993; Wilch and others, 1993). Denton and others (1989) suggested that the glaciers are currently in their most extended position within the past 12-14 kyr.

No long-term records of historic glacier change exist for the dry valleys. R.F. Scott's expedition first visited Taylor Valley in 1903 (Scott, 1905) and again in 1913 (Taylor, 1916). Their photographs were used (Péwé and Church, 1962) to assess changes in glacier extent. The results were inconclusive, partly because of the poor perspective of the photographs and partly because of the relatively small change in glacier extent. In the 1970s the New Zealand Antarctic Programme initiated a course of glaciological measurements in the valleys, which included photographs of the glacier termini (Chinn and Cumming, 1983). In anticipation of future photography, small cairns were erected at each camera location and identified by a metal stake. Some of these cairns were also used as a fixed reference to directly measure changes in glacier extent by using a steel tape to determine the distance to the glacier face. Chinn (1998) found that half the glaciers in valleys were advancing and the others were retreating. No measurements were made in Taylor Valley.

Our study area is Taylor Valley, a $34 \mathrm{~km}$ long valley blocked in the west by Taylor Glacier, an outlet glacier from the EAIS (Fig. 1). To the east, the valley is open to McMurdo Sound. The Asgard Range, which rises to $2000 \mathrm{~m}$, borders the valley to the north, and the Kukri Hills, rising to $1000 \mathrm{~m}$, define the valley's southern edge. The equilibrium-line altitude of the glaciers rises steeply to the west because of the sharp gradient in snow accumulation and sublimation (Fountain and others, 1999).

\section{GLACIER PHOTOGRAPHY}

\subsection{Methods}

During the austral summers of 1972/73 and 1977/78, three glaciers in Taylor Valley were photographed (Fig. 2) using a tripod-mounted camera with a $50 \mathrm{~mm}$ focal-length lens (Chinn and Cumming, 1983). The three glaciers are Canada Glacier, an alpine glacier $33.8 \mathrm{~km}^{2}$ in area; Suess Glacier, $12.2 \mathrm{~km}^{2}$ in area, which abuts against a large hill and spreads along the valley axis in two small lobes; and Taylor Glacier, an outlet glacier of the EAIS. We located the cairns established in the 1970s and, using the original photographs to capture the same scenes, we rephotographed (1995-97) the glaciers using a hand-held camera in a level position. The same-sized focal length lens $(50 \mathrm{~mm})$ was used as in the earlier photography. Small differences in vertical angle between the tripod and hand-held methods do not significantly affect the apparent glacier outline in the photographs. The fixed objects in the background (boulders, mountain peaks) of the photographs were used as reference points against which the position of the glacier outline was compared. We calculated the differences between the current and past glacier positions by measuring the true

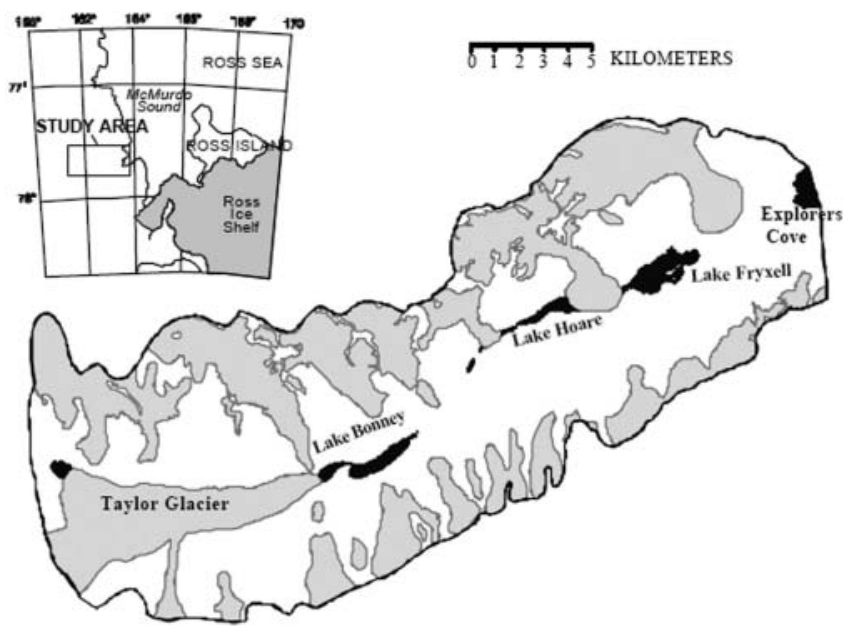

Fig. 1. Map of Taylor Valley, McMurdo Dry Valleys, Antarctica.

distances in the field and apparent distances from the photographs between the cairns, reference points and glaciers (see Appendix).

\subsection{Results and discussion}

The approach seems to work well in that the estimated errors are substantially smaller, in most cases, than the magnitude of the change (Table 1). Two of the three glaciers measured advanced substantially. The change (advance) in Taylor Glacier is at least an order of magnitude greater than the observed changes of the other two glaciers. This might be expected because Taylor Glacier is an outlet glacier of the EAIS and is much larger than the alpine glaciers. In terms of fractional change in length relative to total length, the changes in Taylor and Canada Glaciers are quite similar, $0.11 \%$ and $0.17 \%$, respectively.

Suess Glacier, on the other hand, is retreating. However, the retreat is probably due to local effects rather than a dynamic response of the glacier. Rock debris avalanches from the adjacent valley wall and mantles much of the east lobe of the glacier (Fig. 2c). The rock enhances ablation by reducing the albedo. In contrast, the west lobe of the glacier is free of rock debris, and its bulbous front with an ice cliff (not shown) seems to be advancing. A similar line of reasoning applies to Canada Glacier. The northwestern margin of the glacier (Fig. 2b) advanced $17 \mathrm{~m}$ and coincides with relatively clean ice. The southwestern margin (Fig. 2a) is affected by debris and advanced about $2 \mathrm{~m}$.

Note that all glaciers observed in Taylor Valley are thinning. This is expected for the retreating lobe of Suess Glacier, but it is unusual for advancing glaciers. If the geometry of a glacier front is thought of as a wedge, then as the glacier advances past a fixed point in space the surface elevation will increase at that point. The thinning is probably due to increasing air temperatures, causing increased melting, as inferred from lake-level rise and thinning lakeice covers (Wharton and others, 1992).

Changes in glacier length are slow compared to changes in surface energy balance due to the relatively long response time of glaciers to changes in ice mass (Jóhannesson and others, 1989). For Canada Glacier, given current climatic conditions, the dynamic response time is about $10^{3}$ years. Thus, the glacier advance observed today is a response to conditions over the past 1000 years. Lyons 


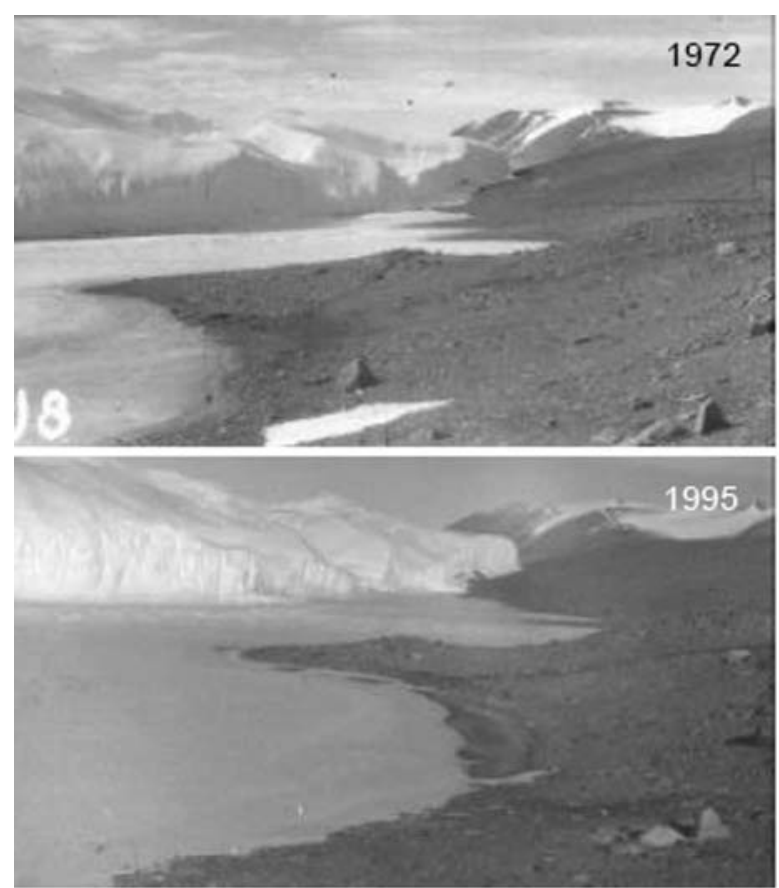

a

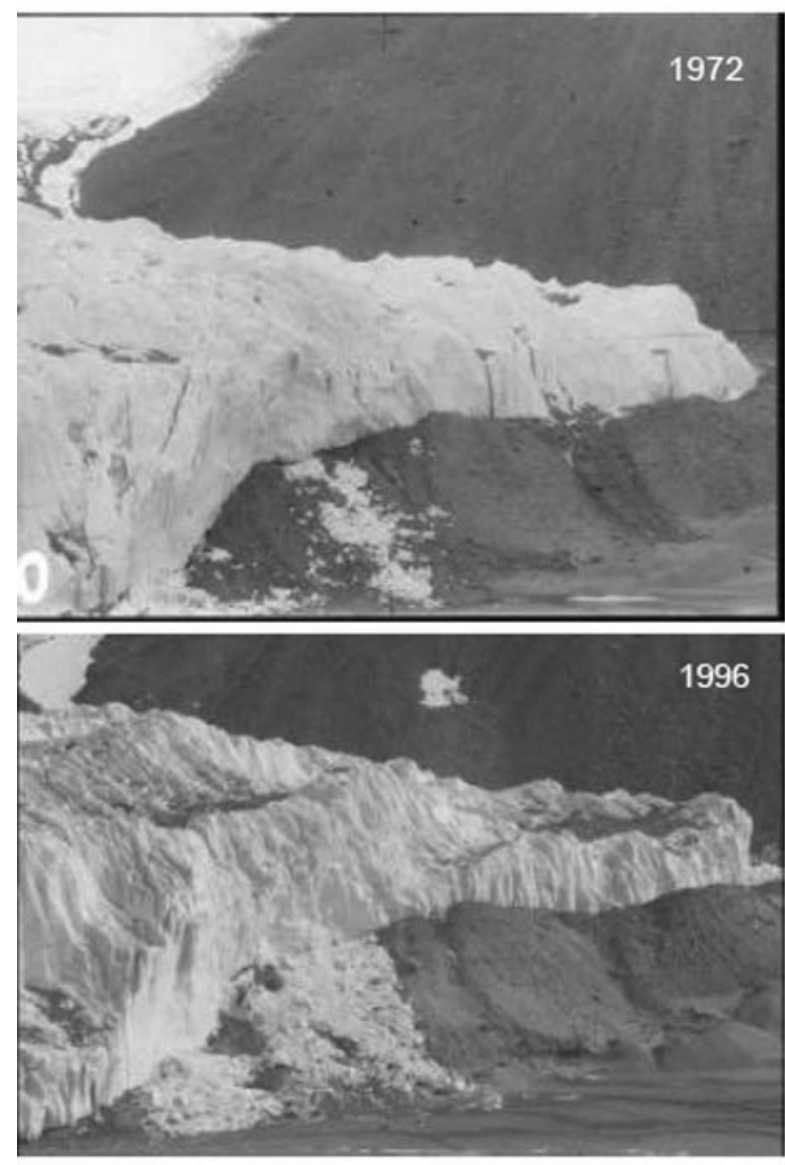

C
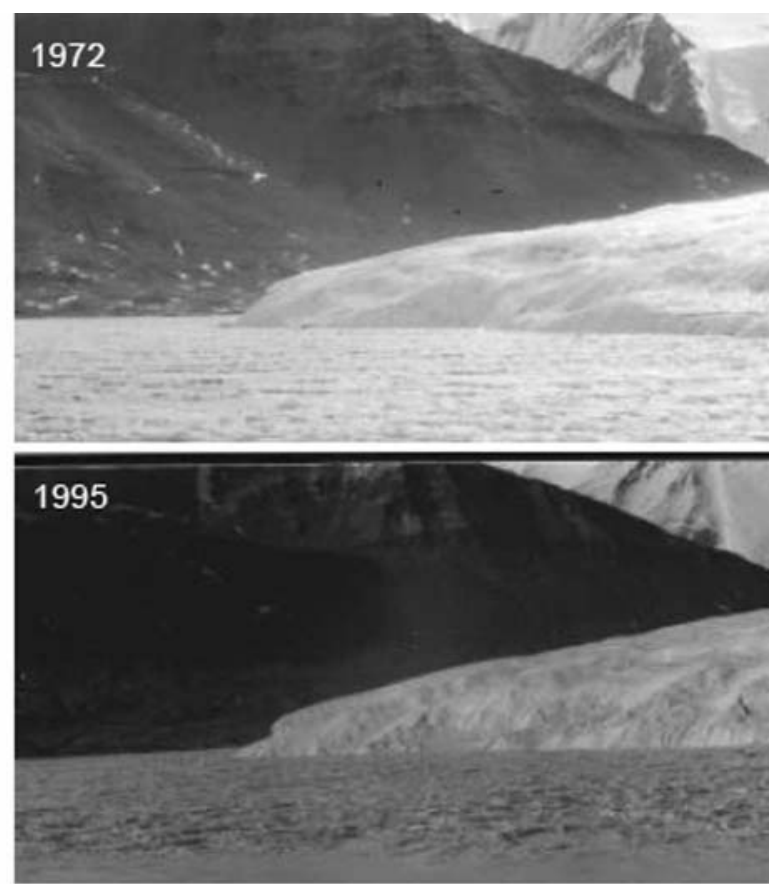

b
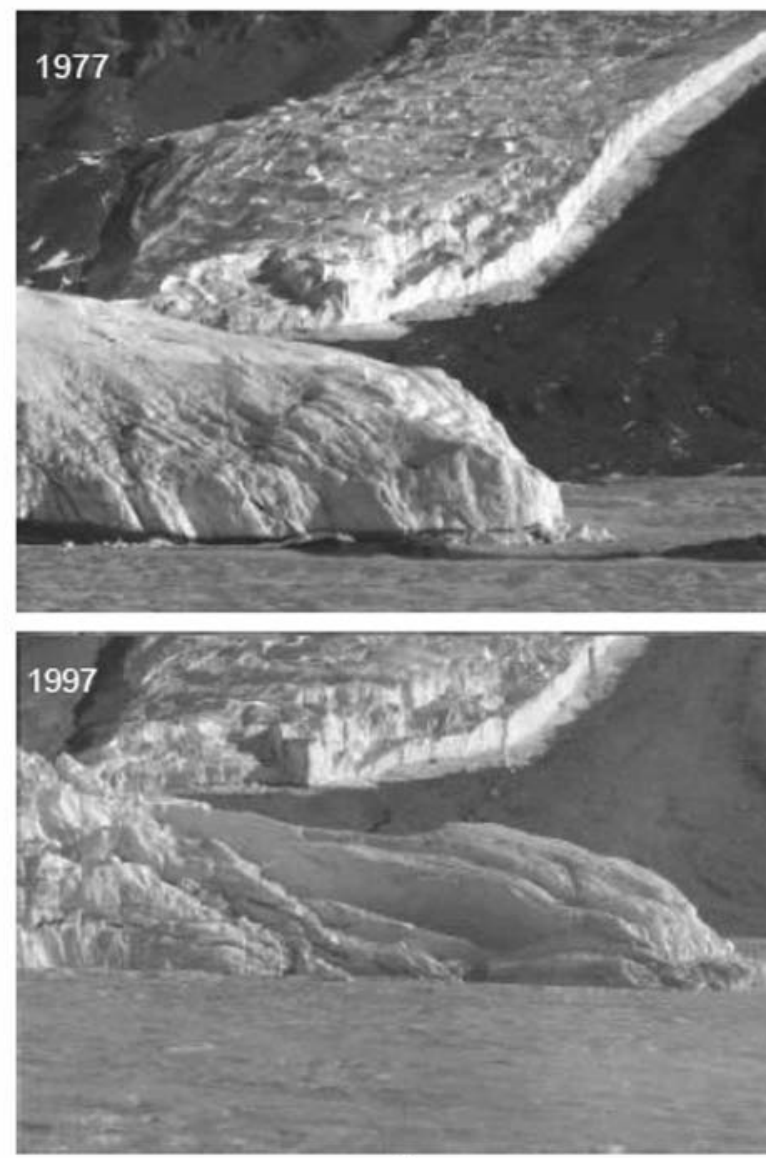

d

Fig. 2. Original photographs of glacier change: (a) Canada Glacier looking east, 1972-95; (b) Canada Glacier looking north, 1972-95; (c) Suess Glacier looking north, 1972-96; and (d) Taylor Glacier looking north, 1977-97. In (a) note the lake level rise with respect to the rocks in the foreground. In (d) the glacier in the background is Rhone Glacier.

and others (1998) infer a drawdown 1200 years ago of the lakes in Taylor Valley. Conditions were colder then by about $3^{\circ} \mathrm{C}$, based on temperature reconstruction from measurements in boreholes drilled into the valley floor (personal communication from G. Clow, 1998). Presumably, colder temperatures reduced meltwater production and inflow to the lakes, and lake levels dropped as the ice covers sublimated. Without meltwater inflow to the lakes, 
Table 1. Changes in terminus position and glacier surface elevation determined from photographic analysis

\begin{tabular}{lccccc}
\hline Glacier & View & Years & Terminus & Surface & Distance \\
& & & $\mathrm{m}$ & $\mathrm{m}$ \\
\hline Taylor & North & $20(1976-96)$ & $+100 \pm 11$ & $-0.38 \pm 0.13$ & 600 \\
Suess & North & $24(1972-96)$ & $-5.4 \pm 0.1$ & $-2.8 \pm 1$ & 300 \\
Suess & West & $24(1972-96)$ & $-2 \pm 1$ & $-1.7 \pm 0.9$ & 100 \\
Canada & North & $23(1972-95)$ & $+17 \pm 2$ & $-6.4 \pm 3$ & 600 \\
Canada & East & $23(1972-95)$ & $+1.9 \pm 0.4$ & $-0.15 \pm 1.22$ & 1000 \\
& & & &
\end{tabular}

Notes: Distance is the distance from the terminus up-glacier over which the change in surface elevation is averaged. The Suess west photograph is not shown in Figure 2 but depicts part of the same lobe in Figure 2c.

which compensates for the mass loss to sublimation, lake volume decreases. Air temperatures warmed following the drawdown, and increased melt from the glaciers refilled the lakes. Perhaps the current trend of increasing lake levels and warmer air temperatures is a continuation of this long-term trend.

If air temperatures increased and glacial melt increased, then we might expect a glacier recession rather than the glacier advances that we observe today. One possible explanation is that with warmer temperatures snowfall increased in the upper reaches of the glaciers, more than compensating for the ablation due to increased melt. Although that is a possibility, there is no evidence linking increased snowfall and warmer temperatures. Also, no evidence exists for an increase in snow accumulation, based on the Taylor Dome ice core, located about $100 \mathrm{~km}$ away (Steig and others, 2000). We hypothesize that the warming air temperatures caused the glacier advance by warming the ice and decreasing its viscosity (Whillans, 1981). To test this hypothesis a numerical model was developed to determine whether the current glacial advance could occur under constant mass-balance conditions with a climatic warming starting $\sim 1000$ years ago. We also test how large an increase in snow accumulation could explain the same result.

\section{ICE-FLOW MODELING}

\subsection{Model description}

We use a finite-difference, time-dependent flowband model of a valley glacier similar to other glacier flow models (Bindschadler, 1982; Waddington, 1982; MacGregor and others, 2000). The model is defined in a coordinate system such that $x$ is the direction of ice flow, $y$ is transverse to ice flow, and $z$ is vertical, positive upwards. $S$ denotes the glacier surface elevation, $B$ denotes the bed elevation, and $H=S-B$ is the ice thickness. Ice flow in the downstream direction is calculated in a flowband of variable width $W(x)$, which parameterizes converging or diverging flow in the $y$ direction. The flowband is essentially bounded by two parallel streamlines across which mass does not flow. The incorporation of a $y$ dimension allows the model to conserve mass within the body of the glacier and it exchanges mass at the surface through the surface mass balance. Glacier thickness changes are calculated by solving the mass continuity equation:

$$
\frac{\mathrm{d} H(x)}{\mathrm{d} t}+\frac{1}{W(x)} \frac{\mathrm{d} Q(x)}{\mathrm{d} x}=\dot{b}(x)
$$

where $Q$ is the ice flux and $\dot{b}$ is the surface specific mass balance. Ice flux is calculated as:

$$
Q(x)=f^{*}(x) u_{\mathrm{s}}(x) W(x) H(x),
$$

where $u_{\mathrm{s}}$ is the surface velocity on the center line, $W H$ is the flowband cross-sectional area and $f^{*}(x)$ is the shape factor, the ratio of velocity averaged over $W H$ to the surface velocity along the center line (Nye, 1965). Surface ice velocity along the center line $u_{\mathrm{s}}$ is calculated assuming ice deformation follows a Glen-type flow law (Glen, 1958).

$$
u_{\mathrm{s}}(x)=\frac{2}{n+1} E(x) \tilde{A}(x)\left(\rho g f \frac{\mathrm{d} S(x)}{\mathrm{d} x}\right)^{n} H(x)^{n+1},
$$

where $n=3$ is the flow exponent, $\rho$ is the ice density, $g$ is the gravitational acceleration, $E$ is an enhancement factor and $\tilde{A}$ is the temperature-independent softness parameter. We assume a no-slip basal boundary. Because drag along the valley walls supports some of the weight of the glacier, a shape factor, $0<f \leq 1$, is used to reduce the basal shear stress (Nye, 1965; Bindschadler, 1982).

The typical expression for the softness parameter, $A(T(z))=A_{0} \exp (-Q / R T(z))$, is a function of temperature, where $T$ is the ice temperature, $Q$ is the activation energy for creep, and $R$ is the gas constant (Paterson, 1994). To simplify the calculations, we use a temperature-independent softness parameter $\tilde{A}$ which generates the same surface velocity as the temperature-dependent softness parameter $A(T(z))$. To determine $\tilde{A}$, we calculate the temperature profile $T(z)$ using a one-dimensional (vertical) steady-state temperature model (Firestone and others, 1990). In this advective-diffusive model of heat flow, the bed is assumed to be below the pressure-melting point, and the surface mass balance, surface temperature and geothermal heat flux are the boundary conditions. The resulting temperature profile, $T(z)$, is used in a temperature-dependent Glen flow law to calculate the surface velocity $u_{\mathrm{s}}$ by integrating from the bedrock $B$ to the surface $S$ :

$$
u_{\mathrm{s}}(x)=2 E(x)\left(\rho g f \frac{\mathrm{d} S(x)}{\mathrm{d} x}\right)^{n} \int_{B(x)}^{S(x)} A(T(x, \zeta))(H(x)-\zeta)^{n} \mathrm{~d} \zeta
$$

We equate the surface velocity using a temperature-dependent softness parameter (Equation (4)) to the surface velocity calculated using a temperature-independent softness parameter (Equation (3)) and solve for $\tilde{A}$ :

$$
\tilde{A}(x)=\frac{(n+1) \int_{B(x)}^{S(x)} A(T(x, \zeta))(H(x)-\zeta)^{n} \mathrm{~d} \zeta}{H(x)^{n+1}} .
$$



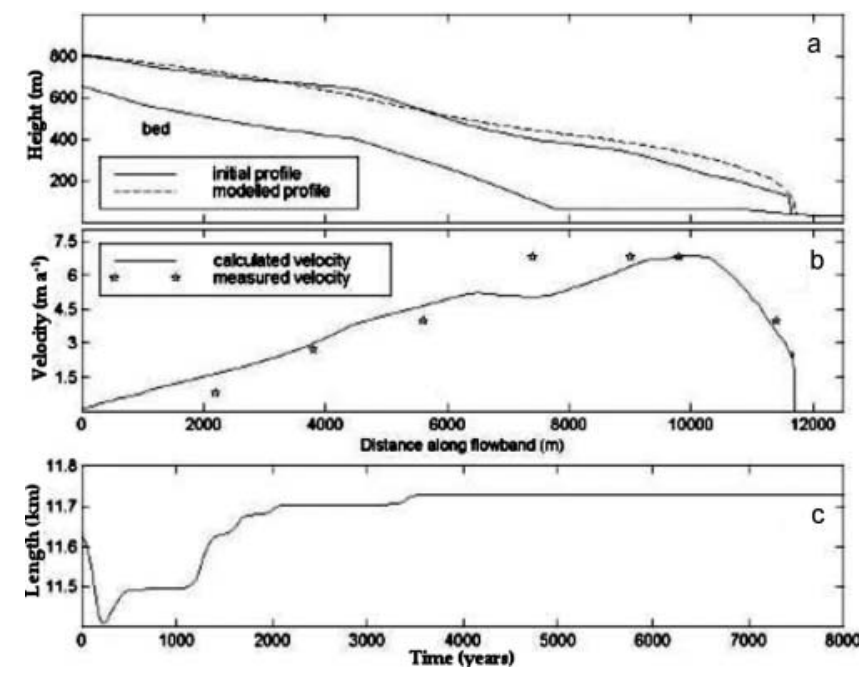

Fig. 3. Comparison of model results and field measurements. The modeled glacier thickness (a) is greater in the ablation zone than the observations, but matches well in the accumulation zone. The velocity profile (b) predicts a localized region of higher velocity than the measurements suggest. Since the overall flow field is not known, it is possible that the measurements were not collected along the central flowline of the glacier. In this case, we expect the true velocities to be somewhat larger than our modeled velocities. The terminus initially retreats as the model reaches equilibrium (c), and then advances to a steady-state position after 4000 years. Our modeled glacier is $75 \mathrm{~m}$ longer than the measured flowline.

We recalculate the flow parameter $\tilde{A}$ any time the ice thickness changes by $>20 \mathrm{~m}$, because ice-thickness changes cause changes in $T(z)$ and corresponding changes in $\tilde{A}$. The value of $20 \mathrm{~m}$ is chosen because we neglect the temperature changes in the upper $20 \mathrm{~m}$ of the glacier due to the seasonal cycle (which we do not model), and focus on longer-term temperature changes which propagate deeper into the glacier and determine ice viscosity.

Historically, the shape factor, $f^{*}$, has been applied to temperate (isothermal) glaciers and relates the measured surface velocity on the center line to the velocity averaged over the glacier cross-section (Nye, 1965). Polar glaciers, like those in the dry valleys, have warmer (and consequently softer) ice near the bed than near the surface. Furthermore, since ice thickness varies along the cross-section, the basal temperature also varies. Thinner ice at the margins of a polar glacier is colder and stiffer relative to the basal ice in the center. Therefore, the shape factor as applied to polar glaciers incorporates two separate effects: channel shape and temperature. The model does not distinguish between these two effects.

\subsection{Model application and results}

We cannot apply the model to Canada, Suess or Taylor Glacier because of the lack of measurements that define glacier depth, surface speed or mass balance. Instead, we examine Commonwealth Glacier, the neighboring glacier to the east of Canada Glacier, where a set of fundamental measurements exists. Commonwealth and Canada Glaciers are similar in that they both flow from the Asgard Range to the floor of Taylor Valley where they form broad fans of ice. Commonwealth Glacier is larger $\left(51.5 \mathrm{~km}^{2}\right)$ than Canada Glacier $\left(33.8 \mathrm{~km}^{2}\right)$, but not much longer, $13 \mathrm{~km}$ vs $11.5 \mathrm{~km}$.
Commonwealth Glacier also appears to be advancing, based on the morphology of the cliffs and position against its moraine (Chinn, 1985). Therefore, Commonwealth Glacier seems a reasonable proxy for the behavior for Canada Glacier.

Our application of the ice-flow model uses measurements of Commonwealth Glacier acquired during the 1995-98 field seasons. Surface elevation $S$ was measured by global positioning system (GPS) surveys; ice thickness $H$ was measured by radio-echo sounding from which bed elevation $B$ was calculated. These data, including mass balance (Fountain, unpublished data), were measured at 20 marker poles drilled into the glacier. Surface velocity was determined through repeat GPS surveying of the marker poles in 1995 and 1997. For the temperature model, we use a geothermal flux of $77 \mathrm{~mW} \mathrm{~m}^{-2}$ (personal communication from G. Clow, 1998) and a single value for the surface temperature of the glacier, $T_{\text {surface }}=-18^{\circ} \mathrm{C}$. Generally, $W(x)$ can be interpolated from the surface velocity field. Since there are relatively few surface velocity measurements on Commonwealth Glacier, we estimate $W(x)$ based on surface topography, and vary $W(x)$ to match the model predictions to measured velocity. We also use an enhancement factor $E(x)$ in Equation (3) to help the model match observations. Grid spacing (in $x$ ) is variable and gradually decreases from $200 \mathrm{~m}$ in the accumulation area to a minimum of $25 \mathrm{~m}$ at the terminus.

The initial geometry used in the model was based on our observations of glacier length, ice thickness, mass balance and flowband width based on the surface velocity field. The initial model used a constant mass-balance gradient with time. The model was run for 15000 years at annual timesteps, and the glacier geometry evolved until an equilibrium length and ice-thickness profile was reached (about 5000 years). Predictions of modern glacier length, surface velocity and ice thickness did not simultaneously match observations in spite of our attempts to adjust the model. Using measured values of $\dot{b}(x)$ and an enhancement factor $E(x)=1$, we were able to match the glacier length and icethickness profile by adjusting $W(x)$, but calculated surface velocities in the 'neck' (Fig. 3) were a factor of 3 too small. To match the measurements of length, surface velocity and ice thickness, we needed to adjust $E(x), W(x)$ and the gradient of mass balance. Ice in the accumulation area needed to be softer than calculated $(E(x)>1)$ and stiffer than calculated in the ablation zone $(E(x)<1)$. The difference may be due to the insulating effect of snow. Model results of heat transfer show that basal ice under the accumulation area is about $1^{\circ} \mathrm{C}$ warmer than when the insulating effect of snow is neglected. A $1{ }^{\circ} \mathrm{C}$ warming reduces the initial estimate of ice stiffness by about $50 \%$, close to our reduction of $40 \%$ used to improve the model fit. The mass-balance gradient used was steeper than observed, with accumulation rate $40 \%$ higher than measured in the accumulation area, and $350 \%$ greater mass loss in the ablation area. Because our interest is the dynamic response time of the glacier (Nye, 1963), we chose to match the observed pattern of $u_{\mathrm{s}}(x)$, at the expense of the massbalance values, the implications of which will be discussed later. The resulting model creates a modern Commonwealth Glacier about $75 \mathrm{~m}$ longer than observed $(0.6 \%$ error), with a similar ice-thickness profile, and similar surface velocities along the center line (Fig. 3). We use this glacier in subsequent perturbation experiments. 


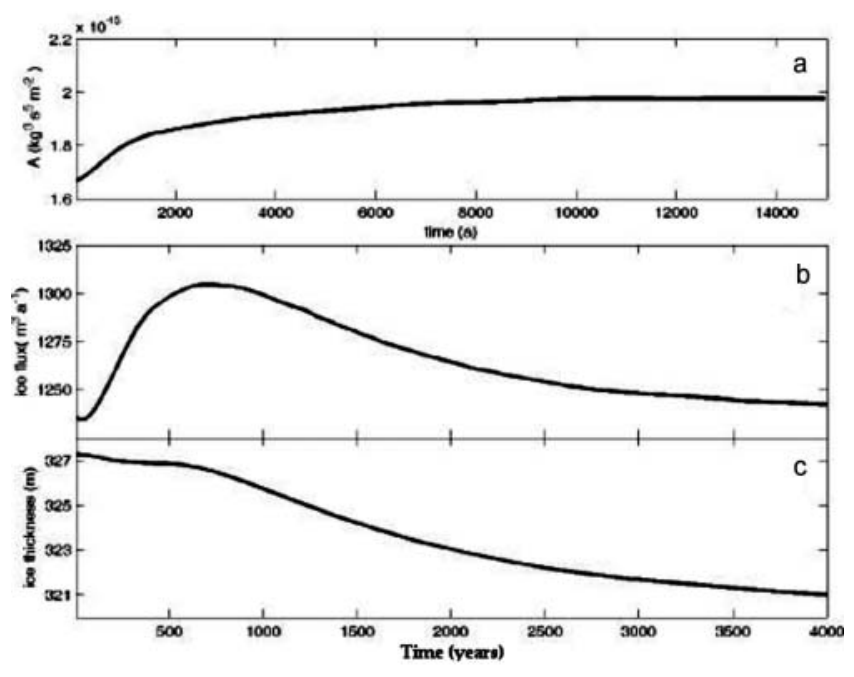

Fig. 4. Responses of softness parameter, ice flux and ice thickness at a point in the neck of the glacier $(x=8800 \mathrm{~m})$ to a $2^{\circ} \mathrm{C}$ warming at the glacier surface. The softness parameter (a) changes exponentially between the initial and final values as the warming penetrates the ice with a characteristic time-scale $\tau$ of 2000 years. The changes of both the ice flux (b) and ice thickness (c) reach a maximum value after $\sim 600$ years. Both ice flux and thickness approach final values asymptotically $(\tau \approx 2000$ years).

\subsection{Glacier response to temperature changes}

To investigate the dynamic response to a change in air temperature alone, we apply a step change to the surface temperature while holding the mass balance constant. A time-dependent advective-diffusive model of heat flow (Patankar, 1980) tracks temperature changes in the ice. The temperature profile of the glacier $T(x, z)$ is recalculated every 25 years, and the flow parameter $\tilde{A}(x, z)$ is updated accordingly. Results show that the terminus position of the glacier responds modestly to temperature perturbations of 1 , 2 and $3{ }^{\circ} \mathrm{C}$ (warming and cooling). Over a 4000 year time interval, the terminus advances by $50 \mathrm{~m}$ for a $3^{\circ} \mathrm{C}$ warming, $25 \mathrm{~m}$ for a $2^{\circ} \mathrm{C}$ warming and is stable for a $1^{\circ} \mathrm{C}$ warming. It is possible that a finer grid resolution might capture more details of terminus movement, but we believe that finer grid spacing is not warranted, given the limitations of the model, and relatively sparse surface data. Figure 4 shows the changes in the softness parameter $\tilde{A}$, ice flux $Q$ and ice thickness $H$ at a point in the 'neck' of the glacier $(x=8800 \mathrm{~m})$ as a result of a $2{ }^{\circ} \mathrm{C}$ warming. The softness parameter (Fig. 4a) changes exponentially, with a characteristic time $\tau$ of 2000 years. As the ice warms and softens, ice flux $Q$ (and ice velocity) initially increases and reaches a maximum after 750 years (Fig. 4b). As a result of mass continuity (Equation (1)) ice thickness $H$ decreases (Fig. 4c). Following the initial maximum in $Q$, both $Q$ and $H$ decrease exponentially, with similar characteristic times of 1800 years.

Glacier length does not change significantly after step decreases in surface temperature of up to $3^{\circ} \mathrm{C}$. Figure 5 shows the changes in $\tilde{A}, Q$ and $H$ due to a $2{ }^{\circ} \mathrm{C}$ cooling evaluated in the neck of the glacier $(x=8800 \mathrm{~m})$ as in Figure 4 . The softness parameter decreases exponentially with the same time constant (Fig. 5a) as in the warming case ( $\tau=2000$ years) and leads to a decrease in $Q$ (Fig. 5b). Ice flux reaches a minimum about 750 years after the step
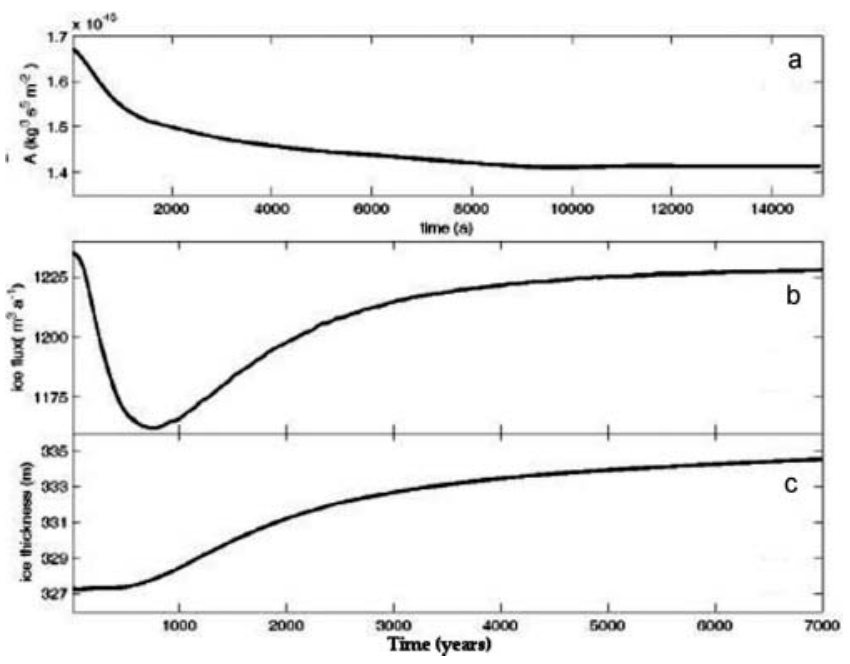

Fig. 5. Responses of softness parameter, ice flux and ice thickness to a $2{ }^{\circ} \mathrm{C}$ cooling at the glacier surface. The softness parameter (a) changes exponentially between the initial and final values as the cooling penetrates the ice ( $\tau=2000$ years). The ice flux (b) reaches a minimum after 750 years as a result of the decrease in softness. This reduction in ice flux leads to a gradual increase in thickness (c). As thickness increases, ice flux increases, reaching pre-cooling levels after 7000 years. This balance between thickness and ice flux prevents any advance or retreat of the terminus in response to cooling.

change in surface temperature. As a result of the reduction in $Q, H$ (Fig. 5c) begins to increase after about 600 years. The gradual increase in $H$ causes in a gradual increase in $Q$ to pre-cooling levels after about 5000 years due to the relationship between ice flux and ice thickness (Equation (2)).

\subsection{Glacier response to mass-balance changes}

To investigate the dynamic response to a change in mass balance, we apply a step change to the mass balance. We use a time-dependent advective-diffusive model of heat flow (Patankar, 1980) to track temperature and viscosity changes resulting from ice-thickness changes, but we keep the surface temperature fixed at $-18^{\circ} \mathrm{C}$.

We find that increasing the accumulation rate in the accumulation area by $7.5 \mathrm{~mm} \mathrm{a}^{-1}(\sim 10 \%$ increase over currently measured values) produces a $25 \mathrm{~m}$ advance, the same as predicted for a $2{ }^{\circ} \mathrm{C}$ warming. Ice thickness and ice flux reach new steady-state values after about 2000 years. In the neck of the glacier, the model predicts that the ice thickness will increase by about $3 \mathrm{~m}$, somewhat less than the thickness increase caused by a $2{ }^{\circ} \mathrm{C}$ cooling. This time-scale is similar to the time required for kinematic wave propagation from the accumulation zone described by Nye (1963). The time required for thermal equilibration is much longer than the kinematic time-scale. Consequently, the glacier geometry reaches a new steady state faster after an accumulation rate perturbation than after a thermal perturbation.

\section{DISCUSSION}

The mismatch between the model results and the measured thickness, length, speed and mass-balance gradient on the glacier is curious. To explain the mismatch, we consider three contributing factors. First, shape factors were used to distribute the stress along the glacier cross-section (Nye, 
1965); these factors were developed for temperate (isothermal) glaciers. Polar glaciers are not isothermal, and have temperature gradients vertically through the ice column and horizontally along the bed. The stress distribution may be different in polar glaciers compared to isothermal glaciers as a result of non-uniform ice temperature, such that the shape factors should be revised for use in polar glaciers. We have relatively little information about the channel shape, iceflow velocity or surface temperature at Commonwealth Glacier, so we do not attempt to revise the shape factors.

Second, the mass-balance gradient required to achieve a realistic glacier length is significantly larger than the measured gradient. The accumulation zone requires a $40 \%$ increase in net balance, and the ablation zone requires a $350 \%$ decrease. In absolute terms, the difference is not large, only $2.25 \mathrm{~cm}$ (from $5.50 \mathrm{~cm}$ to $7.75 \mathrm{~cm}$ ) and $-25 \mathrm{~cm}$ (from $-8 \mathrm{~cm}$ to $-31 \mathrm{~cm}$ ), respectively. This result indicates that current mass-balance conditions may be insufficient to maintain the present length of the glacier. The required mass-balance gradient results in a greater ablation rate in the ablation zone and greater melting because the ablation due to sublimation weakly varies with temperature in comparison to melting (Clow and others, 1988). The notion of a greater balance gradient in the past is partly supported by the observation that our measurements were made in the 1990s during a period of cooling air temperature, reduced meltwater runoff and dropping lake levels (Doran and others, 2002a). This contrasts with previous decades of rising lake levels and the inferred rise since Scott's expedition in 1903 and since modern observations began in the 1970s (Chinn, 1993).

Finally, there is uncertainty in both the flow velocity and depth of Commonwealth Glacier. A total of 20 point values of velocity and ice thickness at the mass-balance stakes does not provide the spatial density required to accurately resolve either glacier depth or flow speed. Given these limitations, the model results may not produce a numerically precise prediction of glacier change with temperature but will provide a reasonable representation of glacier behavior.

The model shows a $25 \mathrm{~m}$ advance for an increase in ice temperature of $2^{\circ} \mathrm{C}$, at the limit of the model's resolution. If there was a temperature increase about 1200 years ago, according to Figure 4, ice flux in the 'neck' should have reached a maximum after $\sim 750$ years, and should now be declining slowly. The ice viscosity should have achieved about half the total anticipated reduction by now as well. Based on this model, we expect another few meters of drawdown in the 'neck' and an associated gradual reduction in ice flux. This model also predicts thinning over the entire ablation zone. The ice thickness in the ablation zone initially increases, reaching a maximum after $\sim 800$ years. The thickness increase is followed by a thinning of approximately $4 \mathrm{~m}$ over the next few thousand years.

Our model also predicts a $25 \mathrm{~m}$ advance for an accumulation rate increase of $7.5 \mathrm{~mm}$ in the accumulation area. If there was an accumulation rate increase 1200 years ago, the ice flux and ice thickness in both the 'neck' and ablation area should still be increasing slowly. The model predicts a total ice-thickness increase of approximately $7 \mathrm{~m}$ in the ablation area, half of which is yet to come over the next 2500 years. This result contrasts with the predictions of the warming-driven advance described above. Our photographic work suggests that the glacier termini are thinning, rather than thickening. This supports a temperature-driven advance rather than an accumulation rate-driven advance. Future measurements should be able to distinguish between these two possibilities.

Although the total predicted advance is small relative to changes in temperate glaciers and to changes in the outlet glaciers of the EAIS, this small advance can play a major role in the hydrology and ecology of Taylor Valley. If Canada Glacier retreats about $10 \mathrm{~m}$, Lake Hoare will flow into Lake Fryxell, thus eliminating one of the three major lakes in the valley. In addition to the disappearance of a lake ecosystem, a long stream channel, passing through the former lake basin, will be created. Water losses to evaporation and to the hyporheic zone (Gooseff and others, 2003) will alter the water, chemistry and nutrient fluxes to Lake Fryxell (McKnight and others, 1999).

The flowband model illustrates the sluggish response of polar glaciers to relatively large changes in air temperature and supports similar results by Whillans (1981). These results, perhaps, are expected from polar glaciers where the ice temperature is well below freezing and mass exchange is small. A $2{ }^{\circ} \mathrm{C}$ warming results in a $25 \mathrm{~m}$ advance of the glacier over a period of about 2000 years. In contrast, a $2{ }^{\circ} \mathrm{C}$ cooling does not result in a retreat, but rather a thickening of the glacier. These dynamic responses contrast with those of temperate glaciers. Also our work demonstrates that polar glaciers can readily advance but retreat slowly. Certainly, we ignore any possible effects of the change in air temperature on mass balance, but there is no clear linkage between the two for temperatures well below freezing. Only if the summer air temperature rises above freezing does ablation dramatically increase. Also, for glaciers that flow onto the relatively flat valley floors, changes in lateral extent are not accompanied by significant changes in elevation.

Previous work indicates that about $50 \%$ of the glaciers in the McMurdo Dry Valleys are advancing (Chinn, 1998). Most likely the differences can be explained by differences in glacier size (thickness). For example, smaller thinner glaciers in the valleys have a shorter response time and temperature-induced advance may have occurred some time in the past. Conversely, for very large glaciers, the advance might just be starting. A more complete answer to this question will require detailed study of both the small and large glaciers in the region.

\section{CONCLUSIONS}

Combining ground-based photography with field-based survey measurements allows us to calculate changes in glacier extent with known precision. In so doing we take advantage of archived photographs acquired decades ago to reveal slow changes inherent to the polar glaciers of the McMurdo Dry Valleys. While all glaciers are observed to be thinning, two of the three glaciers photographed have advanced. While these advances seem to indicate cooler conditions in this part of Antarctica compared to other areas of Antarctica (Doran and others, 2002a) and contradict global trends of glacier shrinkage (Dyurgerov and Meier, 2000), we propose that the advancing glaciers are caused by long-term climate warming.

We hypothesize that a reduction in ice viscosity, due to warmer temperatures, results in glacier expansion and thinning. To test this hypothesis we developed a flowband model of glacier movement, which incorporates a temperature-dependent softness parameter. Results show that an 
increase in air temperature eventually softens the ice as the temperature change is conducted through the glacier. Consequently, the glacier thins and advances about $25 \mathrm{~m}$ for a $2{ }^{\circ} \mathrm{C}$ temperature increase. However, the response is not symmetric for a temperature decrease; the glacier remains in its extended position and thickens to a new equilibrium condition. This behavior is unique to polar glaciers. Furthermore, the modeling indicates that current glacier advance could be the result of a warming 1200 years ago, inferred from other studies (Lyons and others, 1998; G. Clow, unpublished information), with the maximum rate of advance peaking roughly 450 years ago. An accumulation rate increase could also be responsible for the advance. However, the model predicts glacier thickening as a result of an accumulation rate increase, in contrast to the thinning observed in the photography.

Perhaps equally intriguing is the difficulty in matching the model results with the observed values of mass balance, velocity, glacier extent and flow speed. Although the sparse dataset of field measurements and the formulation of the shape factor may contribute to the mismatch, different climatic conditions during the measurement period compared to previous decades to centuries cannot be excluded. Support for this notion is provided by the recent decline in air temperatures and lake levels during the measurement period in contrast to previous decades. Taken together, our findings indicate that the dynamic behavior of temperate glaciers in response to temperature changes cannot be directly applied to polar glaciers. The impressively sluggish behavior of polar glaciers is a consequence of the ice temperature and the small magnitude of mass exchange. These conditions mask an intriguing and complex response to temperature change that should be more thoroughly investigated.

\section{ACKNOWLEDGEMENTS}

Discussions with E. Waddington and $\mathrm{H}$. Conway were valuable to our conception and treatment of this topic. P. Langevin took the photographs in the 1990s and made the enlargements. Reviews by J. Walder and K. Cuffey helped to clarify the manuscript. This work was supported by the US National Science Foundation (NSF) Office of Polar Programs (OPP 9211773 and OPP 0096250).

\section{REFERENCES}

Bindschadler, R. 1982. A numerical model of temperate glacier flow applied to the quiescent phase of a surge-type glacier. J. Glaciol., 28(99), 239-265.

Bull, C. and R. Carnein. 1970. The mass balance of a cold glacier: Meserve Glacier, south Victoria Land, Antarctica. International Association of Hydrological Sciences Publication 86 (Symposium at Hanover 1968-Antarctic Glaciological Exploration (ISAGE)), 429-446.

Chinn, T.J. 1980. Glacier balances in the Dry Valleys area, Victoria Land, Antarctica. International Association of Hydrological Sciences Publication 126 (Riederalp Workshop 1978-World Glacier Inventory), 237-247.

Chinn, T.J.H. 1985. Structure and equilibrium of the Dry Valleys glaciers. New Zealand Antarctic Record, 6, Special Supplement, 73-88.

Chinn, T.J. 1993. Physical hydrology of the Dry Valley lakes. In Green, W.J. and E.I. Friedmann, eds. Physical and biogeochemical processes in Antarctic lakes. Washington, DC, American Geophysical Union, 1-51. (Antarctic Research Series 59.)
Chinn, T.J. 1998. Recent fluctuations of the Dry Valleys glaciers, McMurdo Sound, Antarctica. Ann. Glaciol., 27, 119-124.

Chinn, T.J.H. and R. Cumming. 1983. Hydrology and glaciology, Dry Valleys, Antarctica: annual report for 1978-1979. Christchurch, New Zealand, Ministry of Works and Development. Water and Soil Science Center. (Report WS 810.)

Clow, G.D., C.P. McKay, G.M. Simmons, Jr and R.A. Wharton, Jr. 1988. Climatological observations and predicted sublimation rates at Lake Hoare, Antarctica. J. Climate, 1(7), 715-728.

Cuffey, K.M. and 8 others. 2000. Entrainment at cold glacier beds. Geology, 28(4), 351-354.

Denton, G.H. and B.L. Hall. 2000. Special issue. Glacial and paleoclimatic history of the Ross ice drainage system of Antarctica. Preface. Geogr. Ann., 82A(2-3), 139-141.

Denton, G.H., J.G. Bockheim, S.C. Wilson and M. Stuiver. 1989. Late Wisconsin and Early Holocene glacial history, inner Ross embayment, Antarctica. Quat. Res., 31(2), 151-182.

Doran, P.T. and 12 others. 2002a. Antarctic climate cooling and terrestrial ecosystem response. Nature, 415(6871), 517-520.

Doran, P.T. and 6 others. 2002b. Climate observations from the McMurdo Dry Valleys, Antarctica, 1986-2000. J. Geophys. Res., 107(D24). (10.1029/2001JD002045.)

Dyurgerov, M.B. and M.F. Meier. 2000. Twentieth century climate change: evidence from small glaciers. Proc. Natl. Acad. Sci. U.S.A., 97(4), 1406-1411.

Echelmeyer, K. and Wang Zhongxiang. 1987. Direct observation of basal sliding and deformation of basal drift at sub-freezing temperatures. J. Glaciol., 33(113), 83-98.

Firestone, J., E. Waddington and J. Cunningham. 1990. The potential for basal melting under Summit, Greenland. J. Glaciol., 36(123), 163-168.

Fountain, A.G., G.L. Dana, K.J. Lewis, B.H. Vaughn and D.M. McKnight. 1998. Glaciers of the McMurdo Dry Valleys, southern Victoria Land, Antarctica. In Priscu, J. C., ed. Ecosystem dynamics in a polar desert: the McMurdo Dry Valleys, Antarctica. Washington, DC, American Geophysical Union, 65-75. (Antarctic Research Series 72.)

Fountain, A.G. and 12 others. 1999a. Physical controls on the Taylor Valley ecosystem, Antarctica. BioScience, 49(12), 961-971.

Fountain, A.G., K.J. Lewis and P.T. Doran. 1999b. Spatial climatic variation and its control on glacier equilibrium line altitude in Taylor Valley, Antarctica. Global Planet. Change, 22(1-4), 1-10.

Glen, J.W. 1958. The flow law of ice: a discussion of the assumptions made in glacier theory, their experimental foundation and consequences. International Association of Hydrological Sciences Publication 47 (Symposium at Chamonix 1958-Physics of the Movement of the Ice), 171-183.

Gooseff, M.N., D.M. McKnight, R.L. Runkel and B.H. Vaughn. 2003. Determining long time-scale hyporheic zone flow paths in Antarctic streams. Hydrol. Processes, 17(9), 1691-1710.

Hall, B.L. and G.H. Denton. 1995. Late Quaternary lake levels in the dry valleys, Antarctica. Antarct. J. U.S., 30(5), Review 1995, 52-53.

Hall, B.L., G.H. Denton, D.R. Lux and J.G. Bockheim. 1993. Late Tertiary Antarctic paleoclimate and ice-sheet dynamics inferred from surficial deposits in Wright Valley. Geogr. Ann., 75A(4), 239-267.

Hall, B.L., G.H. Denton and C.H. Hendy. 2000. Evidence from Taylor Valley for a grounded ice sheet in the Ross Sea, Antarctica. Geogr. Ann., 82A(2-3), 275-303.

Hendy, C.H., T.R. Healy, E.M. Rayner, J. Shaw and A.T. Wilson. 1979. Late Pleistocene glacial chronology of the Taylor Valley, Antarctica, and the global climate. Quat. Res., 11(2), 172-184.

Higgins, S.M., G.H. Denton and C.H. Hendy. 2000. Glacial geomorphology of Bonney drift, Taylor Valley, Antarctica. Geogr. Ann., 82A(2-3), 365-389.

Jóhannesson, T., C. Raymond and E. Waddington. 1989. Time-scale for adjustment of glaciers to changes in mass balance. J. Glaciol., 35(121), 355-369. 
Lewis, K.J., A.G. Fountain and G.L. Dana. 1998. Surface energy balance and meltwater production for a Dry Valley glacier, Taylor Valley, Antarctica. Ann. Glaciol., 27, 603-609.

Lyons, W.B., S.W. Tyler, R.A. Wharton, D.M. McKnight and B.H. Vaughn. 1998. A Late Holocene desiccation of Lake Hoare and Lake Fryxell, McMurdo Dry Valleys, Antarctica. Antarct. Sci., 10(3), 247-256.

MacGregor, K.R., R.S. Anderson, S.P. Anderson and E.D. Waddington. 2000. Numerical simulations of glacial-valley longitudinal profile evolution. Geology, 28(11), 1031-1034.

McKnight, D.M., D.K. Niyogi, A.S. Alger, A. Bomblies, P.A. Conovitz and C.M. Tate. 1999. Dry valley streams in Antarctica: ecosystems waiting for water. BioScience, 49(12), 985-995.

Nye, J.F. 1963. On the theory of the advance and retreat of glaciers. Geophys. J. R. Astron. Soc., 7(4), 431-456.

Nye, J.F. 1965. The flow of a glacier in a channel of rectangular, elliptic or parabolic cross-section. J. Glaciol., 5(41), 661-690.

Patankar, S.V. 1980. Numerical heat transfer and fluid flow. New York, Hemisphere Publishing. (D. Reidel Publishing Co.)

Paterson, W.S.B. 1994. The physics of glaciers. Third edition. Oxford, etc., Elsevier.

Péwé, T. L. and R.E. Church. 1962. Glacier regimen in Antarctica as reflected by glacier-margin fluctuation in historic time with special reference to McMurdo Sound. International Association of Hydrological Sciences Publication 58 (Symposium at Obergurgl 1962 - Variations of the Regime of Existing Glaciers), 295-305.

Scott, R.F. 1905. The voyage of the 'Discovery'. Vol. 1-2. London, Smith, Elder.

Steig, E.J. and 7 others. 2000. Wisconsinan and Holocene climate history from an ice core at Taylor Dome, western Ross Embayment, Antarctica. Geogr. Ann., 82A(2-3), 213-235.

Taylor, G. 1916. With Scott: the silver lining. London, Smith, Elder and Co.

Waddington, E.D. 1982. Accurate modelling of glacier flow. (PhD thesis, University of British Columbia.)

Wharton, R.A., C.P. McKay, G.D. Clow, D.T. Andersen, G.M. Simmons and F.G. Love. 1992. Changes in ice cover thickness and lake level of Lake Hoare, Antarctica: implications for local climate change. J. Geophys. Res., 97(C3), 3503-3513.

Whillans, I.M. 1981. Reaction of the accumulation zone portions of glaciers to climatic change. J. Geophys. Res., 86(C5), 4274-4282.

Wilch, T.I., D.R. Lux, G.H. Denton and W.C. Mclntosh. 1993. Minimal Pliocene-Pleistocene uplift of the dry valleys sector of the Transantarctic Mountains: a key parameter in ice-sheet reconstructions. Geology, 21(9), 841-844.

\section{APPENDIX}

To quantify the magnitude of glacier change, we needed to know the position of the fixed features in the background against which the terminus change is compared. For Taylor and Suess Glaciers and one view of Canada Glacier, the fixed features were boulders on the valley wall. In each scene, three boulders were identified on the image, and the distance and orientation from the camera location to each boulder was measured using a total station theodolite. For the eastern view of Canada Glacier (Fig. 2b), three peaks in the background were taken as the fixed points, the distance was estimated from a map, and orientation from the camera location was measured using the theodolite. For all images the distance to the glacier needs to be defined. An imaginary plane, parallel to the photographic (film) plane of the camera, was set equal to the distance from the camera focal point to the glacier horizon observed in the photograph. That distance was also measured by the total station. We assume that the distance does not change during the time intervals between photographs.

Each set of photograph pairs was enlarged to the same photographic scale, approximately equal in real terms to a $200 \mathrm{~mm} \times 250 \mathrm{~mm}$ print. To equalize the scale within each pair, the enlargement was adjusted so the apparent distance between the fixed features in the photos was the same. We assume that during the two-decade interval between photographs the 'fixed' features did not move. While this is certainly true for the mountain peaks, it is possible that the boulders may have moved. To account for this possibility, we compared the geometric relations between boulders on each image pair. In no case did any of the boulders change position during the interval between photographs.

To estimate vertical and horizontal changes in the glacier surface, the position of the fixed features was transformed from their true spatial position to their apparent position in the glacial plane as depicted within the image. The vertical angle to the fixed features is referenced to true horizontal. The angles in the horizontal plane (azimuth) were measured relative to an arbitrary origin $\left(0^{\circ}\right)$ set to the first feature measured. Because the reference angle from the plane of the film in the camera to the first feature was not measured in the field, it had to be determined from the field measurements and photographs. The measured azimuth angles between the fixed features and their apparent horizontal position within the photographic plane (parallel to the camera plane) were used in an iterative procedure to define the reference angle. From the reference angle and measured distances on the photograph, true horizontal distances were calculated using basic geometric relations for similar triangles and the true distances to each feature and to the glacial plane. Vertical elevations were then calculated based on the horizontal distances. The apparent heights of the fixed features above the glacier surface were then determined, and changes in glacier altitude between images were calculated. Numerous values of surface elevation change were calculated along the entire length of the glacier observed in the photograph. These values were averaged and presented as a single number in Table 1.

Photographs flatten perspective (depth of field), so one of the primary sources of error was the precise determination of the glacial plane in the field and the true distance to it. In the field we determined the range of possible distances to the plane. On the photograph the precision to which the distances between features could be measured was about $0.4 \mathrm{~mm}$. Both of these known errors were included in the estimated error in the results. The unknown errors include uncertainty in the depiction of the glacial plane in the image and in possible distortions in the camera lens. We assume that the vector of glacier flow is parallel to the glacial plane, and we believe deviations from this are small. For changes in height of the ice surface, measurements on the photograph were made to the uppermost surface. However, it is clearly possible on a rough glacier surface such elements may be outside the glacier plane. 